AperTO - Archivio Istituzionale Open Access dell'Università di Torino

Should we undertake surveillance for HCC in patients with NAFLD?

This is a pre print version of the following article:

Original Citation:

Availability:

This version is available http://hdl.handle.net/2318/1659231

since 2018-01-26T13:53:01Z

Published version:

DOI:10.1016/j.jhep.2017.10.006

Terms of use:

Open Access

Anyone can freely access the full text of works made available as "Open Access". Works made available under a Creative Commons license can be used according to the terms and conditions of said license. Use of all other works requires consent of the right holder (author or publisher) if not exempted from copyright protection by the applicable law. 


\section{SHOULD WE UNDERTAKE SURVEILLANCE FOR HCC IN PATIENTS WITH NAFLD?}

Ramy Younes ${ }^{1} \mathrm{MD}$ and Elisabetta Bugianesi ${ }^{1} \mathrm{MD} \mathrm{PhD}$

${ }^{1}$ Division of Gastroenterology, Department of Medical Sciences, A.O. Città della Salute e della Scienza di Torino, University of Torino, Torino, Italy.

\section{Address for correspondence:}

Prof. Elisabetta Bugianesi, MD PhD

Department of Medical Sciences

University of Torino

AOU Città della Salute e della Scienza

Corso Dogliotti 14

10126 Torino, Italy

Keywords: steatohepatitis, non-invasive marker, type 2 diabetes, obesity, hepatocarcinogenesis

Word count: 4300

Number of figures: 1

Number of Tables: 2

List of abbreviations: Non Alcoholic Fatty Liver Disease (NAFLD), Non Alcoholic SteatoHepatitis (NASH), Hepatocellular Carcinoma (HCC), Liver Transplantation (LT), Metabolic Syndrome (MetS), Body Mass Index (BMI), Hazard Ratio (HR), Odds Ratio (OR), Type 2 Diabetes Mellitus (T2DM)

Conflict of interest: no conflict of interest by authors for this study 


\section{SUMMARY}

The pandemic spread of obesity and its related complications is rapidly changing the epidemiology of many type of cancers, including Hepatocellular Carcinoma (HCC). Non Alcoholic Fatty Liver Disease (NAFLD) is becoming a main source of HCC, with a steadily rising trend compared to chronic hepatitis due to Virus B, C and alcohol. The much larger spread of the underlying liver disease in the general population and the chance of arising in non-cirrhotic liver are the most worrisome aspects of HCC in NAFLD. Effective screening programs are currently hampered by the limited knowledge of the pathways of carcinogenesis and the lack of tools able to stratify the risk in the NAFLD population. Hence poor surveillance has prevented an adequate treatment of NAFLDrelated HCC so far. Systemic and hepatic molecular mechanisms involved in hepatocarcinogenesis as well as potential early markers of HCC are being extensively investigated. This review describes the current clinical impact of HCC in NAFLD and discusses the most important unmet needs for its effective management.

\section{Word count: 166}




\section{INTRODUCTION}

NAFLD is a complex condition encompassing much more than just liver disease, but in specific albeit partially unknown - conditions, the liver becomes the target of multiple hits stemming from a deranged metabolism, ultimately leading to cirrhosis and risk of primary liver cancer. Hepatocellular carcinoma (HCC) stands as the most overlooked complication of NAFLD and probably the most challenging in clinical practice. This is mainly caused by the large burden of the underlying liver disease, by the chance of HCC in the absence of cirrhosis and by the limitations to treatment due to cardiovascular and metabolic comorbidities. The incomplete knowledge of the mechanisms leading to carcinogenesis in NAFLD hampers the development of markers for targeting subjects at high-risk and contributes to impede an effective care of NAFLD patients with HCC. The aim of this review is to provide updated hints on the surveillance and management of HCC in NAFLD and to highlight the most important unmet needs.

\section{THE BURDEN OF HCC IN NAFLD: PRESENT AND FUTURE}

What is currently known from epidemiological data gives us a perception of the alarming growth of NAFLD as cause of HCC, but does not reliably quantify the entity of the problem, particularly in non-cirrhotic patients. The first evidence of an association between NAFLD and HCC dates back at 1990 (1). Since then, NAFLD is the source of HCC most rapidly increasing, in parallel with the spread of obesity and diabetes across the general population (2, 3). Most data come from cohort studies of HCC management and treatment and from liver transplant databases, while only few population-based studies are available (4-6)(Table 1). In a large study of HCC management in realworld setting including 18031 patients with HCC in 14 countries (2005-2012), NAFLD accounted for $10-12 \%$ of underlying liver diseases in Europe and North America (7). According to data from the Surveillance, Epidemiology and End Results (SEER)-Medicare linked database between 2004 and 2009 (8), NAFLD represented the third most common cause of HCC, after hepatitis C and alcohol-related disease, being diagnosed in $14.1 \%$ of patients with HCC. During the 6-year study period, an overall 9\% annual increase in patients with NAFLD was reported, compared with a 13\% increase in patients with hepatitis C. In a United States population-based study, NAFLD was classified as the most common risk factor for the development of HCC (59\%) with a cumulative incidence of $0.3 \%$ over a 6 -year follow-up (9). In another prospective community-based study which evaluated the outcomes of NASH patients with severe fibrosis (10), $11.3 \%$ of cirrhotic patients developed HCC after a mean follow-up of 7.6 years.

The growing importance of HCC arising in NAFLD is more evident in tertiary centers and it will become obvious after the decline of HCV infection thanks to direct-acting antivirals therapy, 
although it will take decades to occur. A seminal study conducted in Newcastle upon Tyne (U.K.) between 2000 and 2010, reported a more-than-tenfold increase in HCC associated with NAFLD, accounting for 34.8\% of all the cases in 2010 and making NAFLD the single most common underlying etiology (11). Similarly, a study from Germany, which analyzed 162 cases of HCC, identified steatohepatitis as the underlying etiology in $24 \%$ of patients, surpassing chronic hepatitis C (23.3\%), chronic hepatitis B (19.3\%), and alcoholic liver disease (12.7\%) (12). A prospective study assessing 195 OLT candidates for NAFLD-related cirrhosis in from 2003 to 2007 reported an HCC incidence of $12.8 \%$ over a median follow-up of 3.2 years, with a yearly cumulative incidence of 2.6\% (13). Hence, it is not surprising that NAFLD is the most rapidly increasing indication for liver transplantation (LT) due to HCC in U.S. According to the United Network for Organ Sharing (UNOS) registry (14), from 2002 to 2012 the number of NAFLD-related HCC increased of 364\%, becoming the second leading cause of LT after HCV-related cases.

Most studies suggest that the risk of HCC occurrence in NAFLD is lower than in chronic hepatitis C; for example, in a ten-year prospective study, HCC developed in 10 out of 149 patients with NAFLD-associated cirrhosis compared to 25 out of 147 patients with hepatitis C-associated cirrhosis (15). Overall, the 1-year cumulative incidence of HCC in patients with NAFLD has been estimated at around 2.5\% compared with $4 \%$ in patients with hepatitis C, while the 5-year incidence rises to $11 \%$ and $30 \%$ respectively (16). However, the lower prevalence and incidence of HCC in NAFLD must be outweighed by the much larger spread in industrialized countries and the steady rise of its risk factors also in developing countries.

Importantly, HCC can also develop in non-cirrhotic NASH, with hundreds of cases reported so far. The initial observation had been made in a single-center pathological study on 128 patients undergoing liver resection for HCC between 1995 and 2007 (17); HCC arising in livers without significant fibrosis occurred more frequently in patients with metabolic syndrome (MetS) and NAFLD (65.5\%) than in patients with known liver disease of other origin (25\%). This peculiar feature has been afterwards confirmed by epidemiological studies. In a U.S. Veterans Administration cohort (18) including 1500 patients with HCC from 2005 to 2010, 194 patients (13\%) had no evidence of cirrhosis but had a higher prevalence of MetS and NAFLD. In the same cohort, the risk of HCC in the absence of cirrhosis was 5-fold higher in patients with NAFLD, compared to those with chronic hepatitis C. In a tertiary center for HCC referral in Northern England (11), those with NAFLD as underlying liver disease had a lower prevalence of cirrhosis (77.2\%) compared with other etiologies. Similar observations have been confirmed in two Japanese studies, where cirrhosis was absent in 38\% of 292 (19) and 49\% of 87 patients (20) with NAFLDrelated HCC respectively. 
Future projections of this scenario must take into account the alarming growth of NAFLD in the pediatric population, bearing an increased risk of liver related complications in adulthood. A longitudinal study (21) including Danish schoolchildren aged 7-13 years showed that each unit increase in BMI z-score will rise by $20-30 \%$ the risk of liver cancer 30 years later. In other words, this means that a 13-year-old boy who weighs $6 \mathrm{~kg}$ more compared to a lean boy of similar height would have a 30\% increased risk of HCC in his mid-life. Similarly, a study in U.S. (22) reported that each unit increase in BMI in the mid-twenties can hasten by four years the occurrence of liver cancer, confirming that obesity in early adulthood is associated with increased risk of developing HCC at a younger age in the absence of other relevant risk factors.

These data on one hand highlight once again the importance of a global policy for the prevention of obesity and its related complication since childhood, but on the other cast a shadow on the usefulness of our current tools for tracking NAFLD patients at high risk for HCC. Effective markers can only stem from the knowledge of the most important risk factors and mechanisms for the development of HCC in NAFLD.

\section{MULTIPLE HITS FOR THE DEVELOPMENT OF HCC IN NAFLD}

Beyond advanced liver disease itself and male gender, several other factors do concur to increase the risk of HCC in NAFLD and can translate into the unpredictable onset of cancer even in a noncirrhotic liver, which is one of the main dilemma of clinical management.

\section{Obesity and Type 2 Diabetes}

Obesity and Type 2 Diabetes (T2DM) have a well-established, independent and cumulative impact in the development of HCC, also in cirrhosis of viral and alcohol-related etiology, as reported in several large-scale epidemiological studies (Table 2), (23, 24). In a seminal population study including 900000 patients in the United States (23), the likelihood of dying from liver cancer in men with a body mass index (BMI) of $35 \mathrm{~kg} / \mathrm{m} 2$ or above over 16 years of follow up was increased by 4.5 -fold compared to the reference group with a normal BMI (18.5 to $24.9 \mathrm{~kg} / \mathrm{m} 2)$. A more recent study in U.K. analyzed primary care data from 5.24 million individuals in the Clinical Practice Research Datalink and found that BMI was positively associated with liver cancer (HR 1.19, 99\% CI 1.12-1.27) but this effect varied by subject's individual characteristics. The association between BMI and liver cancer was more marked in men than women; in men, the risk substantially and linearly increased starting from BMI above $22 \mathrm{~kg} / \mathrm{m}^{2}$, whereas in women more 
modest increases in risk were recorded. Assuming causality, $10 \%$ or more of liver cancers in the general population could be attributable to excess weight (25). A meta-analysis of 11 cohort studies estimated that the risk of HCC is increased by $17 \%$ in overweight and by $89 \%$ in obese subjects, with an average 24\% increase in risk for each $5 \mathrm{~kg} / \mathrm{m} 2$ increase in BMI; when considering males only, the risk of HCC in obesity rises up to $300 \%$ (26).

The association of obesity and risk of incident HCC has an ethnic specificity, as it is observed in white Caucasian, Latino and Asian men, but not in Afro-Americans, suggesting that we should move beyond BMI and evaluate fat-specific depots (27). Visceral fat accumulation is likely to play an important role, particularly in the non-obese population. In the EPIC (European Prospective Investigation into Cancer) cohort, the waist-to-hip ratio, a rough estimate of abdominal fat, predicted better than BMI the incidence of HCC over an 8.6-year follow-up and conferred a threefold HCC risk to subjects in the upper tertile (28).

Similarly to obesity, in diabetes the risk of malignancy is increased by $20 \%$ and it is mostly accounted by HCC (29), with a hazard ratio (HR) of 2.24 in males and 1.94 in females. In an epidemiological study which included $14 \%$ of the United States population, T2DM was associated with a three-fold risk of HCC (30). A meta-analysis indicates a 2.5-fold increase in both HCC prevalence and incidence among patients with T2DM compared with non-diabetic controls, although it is unclear whether diabetes preceded the underlying chronic liver disease (31).

The independent risk of HCC conferred by obesity and diabetes is clear in liver disease related to $\mathrm{HBV}, \mathrm{HCV}$ and alcohol, but not obvious in NAFLD where the features of MetS also promote the onset and progression of the liver damage. In U.K. the rise in cancer incidence and in cases attributed to NAFLD was paralleled by a steady increase of MetS in patients with HCC (11). An Italian multicentre case-control study tried to assess the role of each feature of MetS as HCC promoter in 185 cases of HCC compared with 404 controls (32). In this analysis T2DM was associated with the highest risk for HCC (OR 4.33, 95\% CI 1.89-9.86), followed by obesity (OR 1.97, 95\% CI 1.03-3.79) and overweight (BMI $\left.\geq 25 \mathrm{~kg} / \mathrm{m}^{2}\right)(\mathrm{OR} 1.25,95 \%$ CI 0.72-2.18), while no link was observed with hypertension and hypercholesterolaemia. Combining multiple hallmarks of MetS, the risk of HCC increased in parallel with the number of features considered, reaching an OR of 4.75 (95\% CI 1·75-12·89) in patients who were overweight and had diabetes (32).

\section{Genetic background}

Multiple risk factors related to host phenotype significantly interact with the genetic background to increase the risk of malignancy. The polygenic inheritance of metabolic diseases, including NAFLD, makes difficult the identification of a single genetic mutation responsible for the increased 
risk of HCC. Nevertheless, the PNPLA3 rs738409 [G] risk allele, found in 40\% of the European population, is repeatedly reported to increase about twelve-fold the risk of developing HCC (33); further, among HCC patients, GG homozygosity is also associated with younger age, shorter history of cirrhosis or less advanced liver disease, and more diffuse HCC at diagnosis, hence reduced survival. Other uncommon genetic variants seem to influence HCC development in a fatty liver. The most important is the human telomerase reverse transcriptase (TERT) gene, which is upregulated in human cancer and is a hallmark of HCC in patients carrying loss-of-function TERT mutations (34). Although only a few Single Nucleotide Polimorfisms (SNPs) have been associated with the development of HCC, they are clinically relevant for potential use as markers of HCC in NAFLD in addition to clinical factors, favoring the implementation of screening strategies for high risk patients (35).

\section{Other risk factors}

The combination of metabolic and genetic risk factors above described could be a fertile soil for the malignant degeneration of benign liver lesions, such as hepatocellular adenomas (HCA), also in the absence of cirrhosis. In a French study which analyzed 31 HCC patients who had MetS as the only risk factor, one-third of these cases developed in a preexisting hepatocellular adenoma (36), while a literature review of 1600 adenomas showed that nearly 4\% of them presented HCC features at the time of resection (37). There is an association between the rising prevalence of obesity and MetS and the recent increase in the HCA prevalence, more likely Inflammatory (I-HCA) $(38,39)$. Obesity and MetS has been often associated with multiple and bilobar adenomas, leading to a higher rate of incomplete resection, and with progression of HCA; conversely, stability or regression of tumor burden is described in up to one third of patients complying with lifestyle changes (weight loss $>5 \%$ ) (38). As a result, the prevalence of malignancy within HCA has markedly increased in men since 2000 and MetS has become the most frequent associated condition.

\section{Potential molecular mechanisms}

Mechanisms linking the progression of steatosis to HCC, with or without cirrhosis, are probably more related to the pathogenesis of the underlying disease rather than to fibrosis, with an important role attributed to environmental factors leading to obesity and diabetes. Western high-fat diet can induce the expression of cytokines like IL-6 and TNF $\alpha$ and increase NF- $\kappa B$ activation (40). In a mouse model, disruption of CD4+ mitochondrial function by linoleic acid boosts oxidative damage via high levels of reactive oxygen species (ROS) generated by CD4+ lymphocytes, while on the contrary blockade of ROS can delay the development of HCC (41). Fructose may play an important 
role by increasing lipoperoxidation (42), downregulating the expression of sirtuin-1, involved in the regulation of cellular survival, or altering the intestinal microbioma composition (43). Gut microbioma contributes to hepatic inflammation by increasing intestinal permeability, promoting translocation of bacterial components such as lipopolysaccharides and favoring the activation of the toll-like receptors.

Figure 1 summarizes the possible impact of the risk factors above described over the development of HCC during a lifetime.

\section{HCC SURVEILLANCE IN NAFLD: MORE QUESTIONS THAN ANSWERS}

Poor surveillance is a constant problem for NAFLD patients and liver-related complications can be the presenting features. In a multicenter prospective study in secondary care Italian centers (44), which included 756 patients with HCC related either to NAFLD or HCV, 63\% of patients with NAFLD missed regular surveillance compared with patients with hepatitis $C(p<0.0001)$, resulting in more advanced HCC burden at diagnosis. In a national U.S. cohort study from Veterans Administration hospitals, including 1500 patients who developed HCC from 2005 through 2010, the diagnosis was made by surveillance in only $40 \%$ of patients with NAFLD compared to $80 \%$ of patients with hepatitis C (45). An effective surveillance is further hindered in patients without cirrhosis. In a retrospective analysis of patients diagnosed with HCC in NAFLD between 2003 and 2012, 86\% of patients with HCC in non-cirrhotic liver had a larger nodule size and/or a greater rate of recurrence compared with 14\% of patients with HCC in cirrhosis (36). Similarly, in another case series of 44 patients who developed NAFLD-related HCC between 2010 and 2012, only one patient (out of six) without cirrhosis underwent liver resection, while the late diagnosis impeded curative treatments in the others (46).

Programming an optimal screening strategy for the early detection of HCC in NAFLD is not trivial. According to current knowledge, the phenotype of patients with NAFLD at risk for HCC is predominantly that of an obese male, with history of diabetes and cardiovascular comorbidities, significantly older than patients with HCC of other origins $(47,68)$. This phenotype consistently overlaps with the definition of NAFLD patients that should be screened for NASH according to the recent European clinical practice guidelines (48), and share the same problems: the burden of potential candidates for systemic surveillance and the absence of reliable non-invasive tools and molecular signatures able to stratify the risk in the NAFLD population, de facto leaving many patients undiagnosed and untreated. On top of that, the onset of HCC in non-cirrhotic livers has led to further uncertainties. In consequence, specific recommendations for the surveillance for HCC in patients with NAFLD are currently lacking. The practice of oncologic follow-up on an individual 
basis is supported by three out of five guidelines on the management of NAFLD (48, 49, 50). The guidelines of the Asia-Pacific region suggest the extension of screening to those "cancers whose incidence is increased by MetS,” but without a generalized and standardized program. The most recent EASL-EASD-EASO clinical practice guidelines still indicate that the large number of NAFLD cases at risk of HCC makes systematic surveillance largely impracticable (48).

Surveillance is deemed as cost-effective if the expected risk for incident HCC exceeds a threshold of $1.5 \%$ per year, but epidemiological studies are still inadequate to answer this question. The PNPLA3 rs738409 C>G gene polymorphism might provide patient-risk stratification for tailored HCC surveillance in NAFLD, but it is not considered cost-effective yet (48). Therefore, HCC arising in NAFLD is not reported as a separate identity but included into "other conditions" in the AASLD guidelines for management of HCC (49). However, surveillance by abdominal ultrasound has a suboptimal performance in this kind of patients, with a high rate of under-recognition of small nodules $(51,52)$.

Imaging based criteria for the diagnosis of HCC in non-cirrhotic patients is advised only in chronic hepatitis B, while there is no recommended screening practice in subjects with NASH $(49,53)$. Thus, in this specific subgroup the diagnosis of HCC should be established by liver biopsy. Recent findings suggest that some HCC developing in NAFLD patients could belong to a particular subtype of hepatic tumors with distinct histological features, called "steatohepatitic hepatocellular carcinoma”, characterized by histological hallmarks resembling steatohepatitis, such as steatosis, hepatocyte ballooning, Mallory bodies, and peri-hepatocellular fibrosis (54). However, liver biopsy should be the final step of a well-defined pathway, starting from tracking high-risk subgroups. Recently a scoring system based on age, sex, medical history of diabetes and viral hepatitis, aminotransferases and $\alpha$-fetoprotein was able to identify almost all HCC cases detected by ultrasound in Taiwan high-risk patients (55). The most successful disease management programs are those where both the pathogenesis and the natural history of the disease are well understood, thus requiring the joint efforts of clinical and basic researchers to hopefully improve the early identification of HCC in targeted NAFLD patients.

\section{TREATMENT OF HEPATOCELLULAR CARCINOMA AND OUTCOME IN NAFLD PATIENTS}

Most recent guidelines give the same therapeutic indications for the treatment of HCC (liver transplantation, radiofrequency ablation, chemioembolization, sorafenib), regardless of its etiology (53). However, the first logic consequence of poor surveillance in NAFLD patients is a diminished likelihood of successful treatment for HCC. In the SEER database (8), including 5,748 HCC cases 
of various etiology between 2004 and 2009, factors associated with one-year mortality after HCC diagnosis were older age (HR: 1.02), lower income (HR: 1.33), un-staged tumor (HR: 1.24) and NAFLD (HR: 1.21). In a U.K. referral center for the management of HCC (11), where just 23\% of patients with NAFLD have their HCC detected by surveillance, the majority (62.3\%) presented symptomatically, with larger tumors and at a more advanced TNM stage, so that their median survival was just 7.2 months. Furthermore, locoregional treatments can be limited by technical difficulties in ultrasound detection or by peripheral atherosclerosis, while increased risks for infection, metabolic decompensation and cardiovascular complications can hamper surgical options (56). The drawbacks of older age, higher rate of cardiovascular and metabolic comorbidities and higher rate of unresectable HCC can be partially outweighed by a better preserved liver function or a lower prevalence of cirrhosis in these patients. Thus, in the above mentioned study (44), 19\% of patients with NAFLD-related HCC underwent liver resection compared with $11 \%$ of those with hepatitis $\mathrm{C}$. The same observation had been done in a retrospective cohort in USA assessing the outcome of curative treatments for HCC (34): NAFLD patients had a better hepatic synthetic function than patients with hepatitis $\mathrm{C}$ or alcohol-related liver disease, and were more likely to undergo liver resection $(41 \%$ in the NAFLD group compared with $13 \%$ in the hepatitis $\mathrm{C}$ and alcohol-related liver disease group, $\mathrm{p}=0.002$ ).

In accordance with these data, recent findings suggest that NAFLD patients do not have a different morbidity and mortality compared to other etiologies after surgical treatment for HCC. In a retrospective study comparing NAFLD and HCV patients with HCC, the main predictors of severe morbidity and liver failure rates after liver resection were cirrhosis, major hepatectomy and MELD $>$ 8, but not steatohepatitis (57). Similar observations were made in another study which evaluated the outcome of HCC treatment in 303 patients from 2000 to 2010. After a median follow up of 50 months, no difference was found in recurrence-free survival and overall survival between NAFLD and HCV or alcohol-related HCC, independent of other pathologic factors and type of curative treatment (34). Importantly, from 2002 to 2012 the indication for LT in patients with HCC and NAFLD has increased by nearly fourfold compared to a twofold increase in those with HCV-related HCC (14). However, patients with NAFLD in waiting list for LT usually have a lower MELD score compared with other liver diseases (58). Thus, according to the UNOS database for LT between 2004 and 2013, they are less likely to receive a liver graft at 90 days and one year after registration than patients with HCV or alcoholic liver disease (58). Very high BMI, especially morbid obesity, represents a contraindication to LT and some centers begin to consider obesity treatment like bariatric surgery as preparation for LT. Even though it might be difficult or impossible in patients with end-stage liver disease, preliminary results suggest that combined LT along with sleeve 
gastrectomy might be considered in selected cases (59). After LT, the five-year survival in NAFLD does not differ from non-NAFLD because the greater risk of death from cardiovascular complications and sepsis is outweighed by a lower risk of graft failure (60).

\section{PREVENTION OF HCC IN NAFLD: SOMETHING POSSIBLE?}

Given the burden of the underlying liver disease, it is likely that the crude cost of any screening program will be exceedingly high for healthcare resources, thus prevention is an option to be actively pursued. Despite many uncertainties, available knowledge suggests that HCC in NAFLD develops slowly during a lifetime; however, the earlier the exposure to risk factors, the earlier the onset of malignancy, particularly on a genetically predisposed background. The casual association with other "superimposed hits" along the trajectory to HCC (such as virus, alcohol or adenomas) could hasten its progression (Figure 1). Hence, much of the game is played in the preliminary phases of the liver disease.

First of all, prevention of obesity starting from childhood should be a priority in the agenda of educational programs (particularly in the schools), and of health care providers, including primary practitioners and pediatric specialists. Lifestyle modification can be able itself to change the natural history of the disease. In a prospective cohort study in Taiwan analyzing risk prediction models for HCC ( $n=428584$, HCC=1668) during an average follow-up of 8.5 year, physical activity reduced the risk of developing HCC proportionally to the intensity of exercise and regardless to the etiology of liver disease (61). In another Swiss study on the development of HCC in hepatocyte-specific PTEN-deficient mice with steatosis, regular exercise reduced the mean number and the volume of lesions and decreased tumor cell proliferation, stimulating the phosphorylation of AMPK and decreasing the kinase activity of mTOR (62).

Second, effective therapies to cure NASH can reduce the burden of patients at high risk for developing HCC. The landscape of potentially curative treatments is rapidly growing, as reviewed elsewhere in this issue (..Editorial office)

Lastly, we should not forget possible prevention of HCC by old drugs often prescribed in NAFLD patients. Metformin seems to enhance antitumour mechanisms by mTOR inhibition (63). In a metaanalysis the use of metformin in 105495 patients with T2DM was associated with a 70\% reduction in the risk of HCC (64). A reduction of 50\% in HCC risk was also observed in another metaanalysis including 22650 HCC-patients among 334307 diabetics, while the risk was increased when sulfonylurea or insulin were used (65). Further, metformin can even improve the outcome of HCC treatment: in a prospective Taiwanese study in diabetic patients with early stage HCC undergoing radiofrequency ablation, a lower mortality rate was observed in patients under metformin (66). 
Increasing data also highlight an important role for statins: in a large meta-analysis which collected 4298 cases of HCC among 1.5 milion patients, the use of statins has been associated to a $37 \%$ reduction in HCC incidence (67). All these data suggest that the use of these medications should be encouraged in patients with NAFLD beyond their metabolic and cardiovascular benefits.

\section{CONCLUSIONS}

The growing burden of HCC linked to NAFLD is becoming a serious challenge for public health, in terms of surveillance and treatment. Many questions remain to be answered, including carcinogenesis in non-cirrhotic livers and the best strategy for targeting high-risk subjects in the general population. These open problems currently delay diagnosis and limit the possibility of therapeutic intervention. We need more epidemiological and clinical data and a better understanding of the molecular events leading from obesity to NASH and HCC, particularly in noncirrhotic patients, in order to develop scoring algorithms and serological tests to stratify the risk in NAFLD patients. In the meanwhile, the best and probably sole effective strategy is prevention of the main risk factors for NAFLD through public awareness and education programs.

\section{ACKNOWLEDGMENTS}

Supported by grant from the EPoS (Elucidating Pathways of Steatohepatitis) consortium funded by the Horizon 2020 Framework Program of the European Union under Grant Agreement 634413. 
Table 1. Principal and most recent studies about the association between NAFLD/NASH and HCC.

\begin{tabular}{|c|c|c|}
\hline Author & Study Subjects & Results and Comments \\
\hline \multicolumn{3}{|c|}{ HCC in NAFLD/NASH-related cirrhosis } \\
\hline Bugianesi 2002 (69) & $\begin{array}{l}\text { Analysis of } 44 \text { CC among } 641 \\
\text { patients with cirrhosis of different } \\
\text { etiologies }\end{array}$ & $\begin{array}{l}\text { In CC-related HCC high prevalence } \\
\text { of features of MS have been observed } \\
\text { (T2DM, obesity, dyslipidemia). } \\
\text { NAFLD-related features are more } \\
\text { frequent in HCC arising in CC than } \\
\text { HCC of other origins. }\end{array}$ \\
\hline Marrero 2002 (70) & Analysis of 105 HCC patients. & $\begin{array}{l}\text { NAFLD prevalence among CC- } \\
\text { related HCC was } 13 \% \text {. CC-related } \\
\text { HCC were less likely to have } \\
\text { undergone HCC surveillance and had } \\
\text { larger tumors at diagnosis }\end{array}$ \\
\hline Mittal 2015 (45) & $\begin{array}{l}1.500 \text { patients who developed HCC } \\
\text { from } 2005 \text { through } 2010 \text { from } \\
\text { Veteran Administration hospitals }\end{array}$ & $\begin{array}{l}\text { NAFLD accounted for } 8 \% \text { of total } \\
\text { cases. A higher percentage of } \\
\text { NAFLD-related HCC were not } \\
\text { diagnosed during surveillance } \\
\text { programs. NAFLD is the third most } \\
\text { common risk factor for HCC }\end{array}$ \\
\hline Wong 2014 (2) & $\begin{array}{l}10.061 \text { American adults LT liver } \\
\text { recipients for HCC (2002-2012). A } \\
\text { retrospective study. }\end{array}$ & $\begin{array}{l}\text { From } 2002 \text { to 2012, the number of } \\
\text { patients undergoing LT for NASH- } \\
\text { related HCC increased } 4 \text { folds, much } \\
\text { more than any other HCC etiology. }\end{array}$ \\
\hline Tateishi 2015 (71) & $\begin{array}{l}33.782 \text { HCC cases in } 53 \text { tertiary care } \\
\text { centers in Japan from } 1991 \text { to } 2010\end{array}$ & $\begin{array}{l}\text { The proportion of non-virus-related } \\
\text { HCC cases increased from } 1991 \text { to } \\
2010 \text { ( } 10.0 \% \text { to } 24.1 \%) \text { and most } \\
\text { cases of non-viral HCC are related to } \\
\text { lifestyle factors, including obesity } \\
\text { and T2DM }\end{array}$ \\
\hline
\end{tabular}

HCC in non-cirrhotic liver with NAFLD/NASH

Paradis 2009 (17)
31 HCC patients with MS and no

cirrhosis or causes of cirrhosis
HCC arising in the context of MS were more often well differentiated ( $28 \%$ vs $64.5 \%$ ) and in one third of cases developed in a preexisting liver cell adenoma 


\begin{tabular}{|c|c|c|}
\hline Yasui 2011 (20) & $\begin{array}{l}87 \text { HCC cases in a Multicentre } \\
\text { Japanese study on histologically } \\
\text { proven NASH }\end{array}$ & $\begin{array}{l}\text { HCC arises in } 43 \text { cases with no } \\
\text { established cirrhosis }\end{array}$ \\
\hline Dyson 2014 (11) & $\begin{array}{l}632 \text { English patients with HCC } \\
\text { analyzed between } 2000 \text { and } 2010\end{array}$ & $\begin{array}{l}\text { Most commonly, HCC arising } \\
\text { without cirrhosis are linked to } \\
\text { NAFLD. Diagnosis was made out of } \\
\text { surveillance programs, so patients } \\
\text { presented larger tumors associated } \\
\text { with symptoms. }\end{array}$ \\
\hline Perumpail 2015 (46) & $\begin{array}{l}\text { NAFLD/NASH-associated HCC } \\
\text { arising in the absence of cirrhosis } \\
\text { between January } 2010 \text { and September } \\
2012 \text { from a tumor board database at } \\
\text { Brooke Army Medical Center } \\
\text { (BAMC). }\end{array}$ & $\begin{array}{l}\text { Of } 44 \text { cases of HCC reviewed, } 6 \\
\text { cases of non-cirrhotic HCC } \\
\text { associated with NAFLD/NASH } \\
\text { and/or MS were identified. } \\
\text { The development of this kind of HCC } \\
\text { in the absence of cirrhosis in the US } \\
\text { population raises the important } \\
\text { question of HCC screening for this } \\
\text { at-risk group. }\end{array}$ \\
\hline Mohamad 2015 (36) & $\begin{array}{l}\text { A retrospective analysis on all adults } \\
\text { diagnosed with HCC and NAFLD at } \\
\text { Cleveland Clinic Foundation between } \\
2003 \text { and } 2012 \text {. }\end{array}$ & $\begin{array}{l}36 \text { patients with non-cirrhotic } \\
\text { NAFLD-HCC were compared to } 47 \\
\text { patients with NAFLD-HCC and liver } \\
\text { cirrhosis. } \\
\text { Patients with HCC in the absence of } \\
\text { cirrhosis are more likely to present at } \\
\text { an older age with larger tumor and } \\
\text { have higher rates of tumor } \\
\text { recurrence. } \\
\text { Studies to assess the cost- } \\
\text { effectiveness of HCC surveillance in } \\
\text { this group should be conducted }\end{array}$ \\
\hline
\end{tabular}

CC: cryptogenic cirrhosis; HCC hepatocellular carcinoma; BMI: body mass index; MS: metabolic syndrome; NAFLD: non-alcoholic fatty liver disease; T2DM: type 2 diabetes mellitus; TG: triglycerides; AST: aspartate aminotransferase; ALT: alanine aminotransferase; NASH: non-alcoholic steatohepatitis; LT: liver transplantation. 
Table 2. Principal and most recent studies about the association between HCC, obesity and Type 2 Diabetes mellitus.

\begin{tabular}{|c|c|c|}
\hline Author & Study subjects & Results \\
\hline \multicolumn{3}{|c|}{ HCC and obesity } \\
\hline Calle 2003 (23) & Cohort of 900.000 American adults & $\begin{array}{l}\text { Risk of dying from HCC was } 4.5 \text { times } \\
\text { higher in men with a BMI }>35 \text { compared } \\
\text { to the group with normal BMI. RR } 2.41 \text { in } \\
\text { men ( } 95 \% \text { CI 1.92-3.01) and } 1.47 \text { in } \\
\text { women }(95 \% \text { CI 1.08-2) }\end{array}$ \\
\hline Larsson 2007 (26) & $\begin{array}{l}\text { Meta-analysis of cohort studies of } \\
\text { excess body weight and risk of } \\
\text { HCC from } 1966 \text { to } 2007\end{array}$ & $\begin{array}{l}\text { Summary RR of HCC was } 1.17 \text { (95\% CI } \\
1.02-1.34) \text { for overweight subjects and } 1.89 \\
(95 \% \text { CI } 1.51-2.36) \text { for the obese }\end{array}$ \\
\hline Schlesinger 2013 (28) & $\begin{array}{l}\text { European multicenter trial with } \\
359.525 \text { subjects }\end{array}$ & $\begin{array}{l}\text { Weight increase in adulthood was found to } \\
\text { be a risk factor for HCC (RR 2.48, 95\% CI } \\
1.49-4.13 \text { ) }\end{array}$ \\
\hline Archambeaud 2014 (72) & $\begin{array}{l}905 \mathrm{HCV} / \mathrm{HBV} \text { negative Caucasian } \\
\text { patients with alcoholic or } \\
\text { metabolic cirrhosis collected in } \\
\text { four French centres. }\end{array}$ & $\begin{array}{l}\text { HCC was independently related to past } \\
\text { obesity }(\mathrm{P}=0.007) \text { and diabetes } \\
(\mathrm{P}=0.037) \text {. }\end{array}$ \\
\hline Manal M. Hassan 2015 (22) & $\begin{array}{l}622 \text { patients newly diagnosed with } \\
\text { HCC from } 2004 \text { to } 2013 \text {, compared } \\
\text { to } 660 \text { healthy controls to } \\
\text { determine weights, heights, and } \\
\text { body sizes at various ages before } \\
\text { HCC development or enrollment as } \\
\text { controls. }\end{array}$ & $\begin{array}{l}\text { Obesity in early adulthood is a significant } \\
\text { risk factor for HCC (OR 2.6, 95\% CI 1.4- } \\
4.4 \text { for entire population, 2.3, 95\% CI 1.2- } \\
4.4 \text { for men and 3.6, 95\% CI 1.5-8.9, for } \\
\text { women respectively). } \\
\text { Each unit increase in BMI at early } \\
\text { adulthood was associated with a } 3.89- \\
\text { month decrease in age at HCC diagnosis (P } \\
<.001 \text { ). }\end{array}$ \\
\hline Setiawan 2016 (27) & $\begin{array}{l}\text { Cohort study of more than } 215,000 \\
\text { men and women from Hawaii and } \\
\text { California that was assembled } \\
\text { from } 1993 \text { through } 1996 \text {. After a } \\
\text { median follow-up of } 16.6 \text { years, } \\
482 \text { incident HCC cases were } \\
\text { identified among 168,476 } \\
\text { participants. }\end{array}$ & $\begin{array}{l}\text { BMI was associated with HCC in men (HR } \\
\text { 1.26; 95\% CI, 1.12-1.42) but not in women } \\
\text { (HR, 1.06; 95\% CI, 0.90-1.25) and only in } \\
\text { Japanese, white, and Latino men, while } \\
\text { there was no association in black men. }\end{array}$ \\
\hline \multicolumn{3}{|c|}{ HCC and type 2 diabetes mellitus } \\
\hline
\end{tabular}




\begin{tabular}{|c|c|c|}
\hline Davila 2005 (30) & $\begin{array}{l}\text { 2.061 HCC patients and } 6.183 \text { non- } \\
\text { cancer controls from the } \\
\text { Surveillance Epidemiology and } \\
\text { End-Results Program-Medicare } \\
\text { linked database. Population-based } \\
\text { case-control study }\end{array}$ & $\begin{array}{l}\text { The proportion of HCC patients who had } \\
\text { diabetes }(43 \%) \text { was significantly greater } \\
\text { than controls (19\%). Diabetes increased the } \\
\text { risk for HCC (adjusted OR 2.87, 95\% CI } \\
2.49-3.30 \text { ) }\end{array}$ \\
\hline Inoue 2006 (29) & $\begin{array}{l}\text { Questionnaire to } 97.771 \text { Japanese } \\
\text { subjects }\end{array}$ & $\begin{array}{l}\text { Diabetes led to a higher risk of HCC in } \\
\text { males and females (HR of } 2.24 \text { CI } 95 \% \\
1.64-3.04 \text { and } 1.94 \text { CI } 95 \% 1.00-3.73 \text {, } \\
\text { respectively) and was more strongly } \\
\text { associated with development of HCC } \\
\text { among malignant tumors }\end{array}$ \\
\hline Koh 2013 (74) & $\begin{array}{l}\text { A prospective cohort of } 63.257 \\
\text { Chinese men and women enrolled } \\
\text { in 1993-1998. After a mean } \\
\text { follow-up of } 14 \text { years, } 499 \text { cohort } \\
\text { participants developed HCC. }\end{array}$ & $\begin{array}{l}\text { A history of diabetes at baseline was } \\
\text { associated with an HR of } 2.14 \text { (95\% CI } \\
1.69-2.71) \text {. }\end{array}$ \\
\hline Kasmari 2017 (73) & $\begin{array}{l}\text { A retrospective cohort study, using } \\
\text { the MarketScan insurance claims } \\
\text { database from } 2008-2012 . \\
\text { Individuals with HCC (7.473 } \\
\text { patients) aged 19-64 years and age } \\
\text { and sex-matched controls (22.110 } \\
\text { patients) were included }\end{array}$ & $\begin{array}{l}\text { In the absence of cirrhosis, type II diabetes } \\
\text { (OR 1.353) was an independent risk factor } \\
\text { for hepatocellular carcinoma. }\end{array}$ \\
\hline
\end{tabular}

CC: cryptogenic cirrhosis; CI: confidence interval; HCC hepatocellular carcinoma; RR: relative risk; OR: odds ratio; BMI: body mass index; MS: metabolic syndrome; SIR: standardized incidence ratio; NAFLD: non-alcoholic fatty liver disease; HR: hazard ratio. 
Figure 1. Impact of the main risk factors over the development of HCC during a lifetime.

HCC in NAFLD develops slowly during a lifetime; however, the earlier exposure to risk factors, as childhood obesity, and a genetically predisposed background can hasten its progression and/or increase the risk. The casual association with other "superimposed hits” along the trajectory to HCC (such as virus, alcohol or adenomas) could favour its development in an unpredictable way.

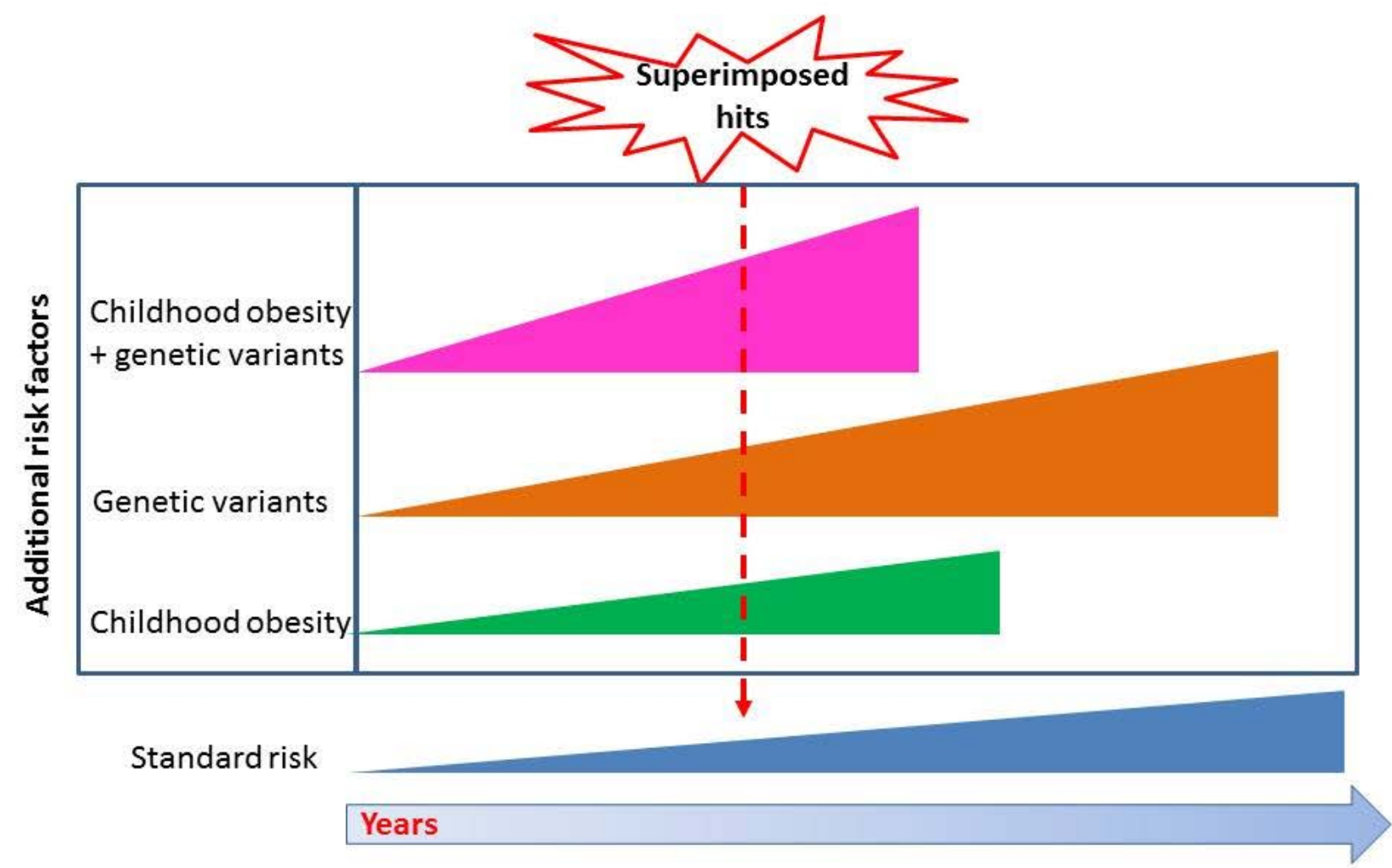




\section{References}

1) Powell EE, Cooksley WG, Hanson R, Searle J, Halliday JW, Powell LW. The natural history of nonalcoholic steatohepatitis: a follow-up study of forty two patients for up to 21 years. Hepatology 1990;11:74-80.

2) Wong RJ, Cheung R, Ahmed A. Nonalcoholic steatohepatitis is the most rapidly growing indication for liver transplantation in patients with hepatocellular carcinoma in the US. Hepatology 2014; 59: 2188-95.

3) Marengo A, Rosso C, Bugianesi E. Liver Cancer: Connections with Obesity, Fatty Liver, and Cirrhosis. Annu Rev Med. 2016;67:103-17.

4) Rafiq N, Bai C, Fang Y, Srishord M, McCullough A, Gramlich T, et al. Longterm follow-up of patients with nonalcoholic fatty liver. Clin Gastroenterol Hepatol 2009;7:234-238.

5) Ekstedt M, Franzen LE, Mathiesen UL, Thorelius L, Holmqvist M, Bodemar G, et al. Long-term follow-up of patients with NAFLD and elevated liver enzymes. Hepatology 2006;44:865-873.

6) Baffy G, Brunt EM, Caldwell SH Hepatocellular carcinoma in non-alcoholic fatty liver disease: an emerging menace. J Hepatol. 2012 Jun;56(6):1384-91.

7) Park JW, Chen M, Colombo M, et al. Global patterns of hepatocellular carcinoma management from diagnosis to death: the BRIDGE study. Liver Int 2015; 35: 2155-66.

8) Younossi ZM, Otgonsuren M, Henry L, et al. Association of nonalcoholic fatty liver disease (NAFLD) with hepatocellular carcinoma (HCC) in the United States from 2004 to 2009. Hepatology. 2015 Dec;62(6):1723-30.

9) Sanyal A, Poklepovic A, Moyneur E, Barghout V. 2010. Population-based risk factors and resource utilization for HCC: US perspective. Curr. Med. Res. Opin. 26:2183-91 
10) Yatsuji S, Hashimoto E, Tobari M, et al. Clinical features and outcomes of cirrhosis due to nonalcoholic steatohepatitis compared with cirrhosis caused by chronic hepatitis C. J. Gastroenterol. Hepatol. 2009. 24:248-54

11) Dyson J, Jaques B, Chattopadyhay D, et al. Hepatocellular cancer: the impact of obesity, type 2 diabetes and a multidisciplinary team. J. Hepatol. 2014 60:110-17

12) Ertle J, Dechene A, Sowa JP, et al. Nonalcoholic fatty liver disease progresses to hepatocellular carcinoma in the absence of apparent cirrhosis. Int J Cancer 2010; 128:2436-2443.

13) Ascha M, Hanouneh IA, Lopez R, et al. The incidence and risk factors of hepatocellular carcinoma in patients with alcoholic steatohepatitis. Hepatology 2010; 51: 1972-78.

14) Wong RJ, Cheung R, Ahmed A. Nonalcoholic steatohepatitis is the most rapidly growing indication for liver transplantation in patients with hepatocellular carcinoma in the U.S. Hepatology 2014; 59:2188-9

15) Sanyal AJ, Banas C, Sargeant C, Luketic VA, Sterling RK, Stravitz RT, et al. Similarities and differences in outcomes of cirrhosis due to nonalcoholic steatohepatitis and hepatitis C. Hepatology 2006;43:682-689

16) Oda K, Uto H, Matawari S, et al. Clinical features of hepatocellular carcinoma associated with non-alcoholic fatty liver disease: a review of human studies. Clin J Gastroenterol 2015; 8: 1-9.

17) Paradis V, Zalinski S, Chelbi E, et al. Hepatocellular carcinomas in patients with metabolic syndrome often develop without significant liver fibrosis: a pathological analysis. Hepatology 2009; 49: 851-59.

18) Mittal S, El-Serag HB, Sada YH, et al. Hepatocellular Carcinoma in the Absence of Cirrhosis in United States Veterans is Associated With Nonalcoholic Fatty Liver Disease. Clin Gastroenterol Hepatol. 2016 Jan;14(1):124-31 
19) Tokushige K, Hashimoto E, Horie Y, et al. Hepatocellular carcinoma in Japanese patients with nonalcoholic fatty liver disease, alcoholic liver disease, and chronic liver disease of unknown etiology: report of the nationwide survey. J. Gastroenterol. 2011; 46:1230-37

20) Yasui K, Hashimoto E, Komorizono Y, et al. Characteristics of patients with nonalcoholic steatohepatitis who develop hepatocellular carcinoma. Clin. Gastroenterol. Hepatol. 2011; 9:428-33

21) Berentzen TL, Gamborg M, Holst C et al. Body mass index in childhood and adult risk of primary liver cancer. J Hepatol. 2014 Feb;60(2):325-30.

22) Hassan MM, Abdel-Wahab R, Kaseb A et al. Obesity Early in Adulthood Increases Risk but Does Not Affect Outcomes of Hepatocellular Carcinoma. Gastroenterology. 2015 Jul;149(1):11929.

23) Calle EE, Rodriguez C, Walker-Thurmond K, Thun MJ. Overweight, obesity, and mortality from cancer in a prospectively studied cohort of U.S. adults. N Engl J Med 2003; 348:1625-1638.

24) Bianchini F, Kaaks R, Vainio H. Overweight, obesity, and cancer risk. Lancet Oncol 2002; 3:565-574.

25) Bhaskaran K, Douglas I, Forbes H et al. Body-mass index and risk of 22 specific cancers: a population-based cohort study of 5·24 million UK adults. Lancet. 2014 Aug 30;384(9945):755-65.

26) Larsson SC, Wolk A. Overweight, obesity and risk of liver cancer: a meta-analysis of cohort studies. Br J Cancer 2007; 97: 1005-08.

27) Setiawan VW, Lim U, Loren L, et al, Sex and Ethnic Differences in the Association of Obesity With Risk of Hepatocellular Carcinoma Clin Gastroenterol Hepatol. 2016 Feb;14(2):309-16.

28) Schlesinger S, Aleksandrova K, Pischon T, et al. Abdominal obesity, weight gain during adulthood and risk of liver and biliary tract cancer in a European cohort. Int. J. Cancer. 2013. 132:645-57 
29) Inoue M, IwasakiM,Otani T, et al. 2006. Diabetes mellitus and the risk of cancer: results from a large-scale population-based cohort study in Japan. Arch. Intern. Med. 166:1871-77

30) Davila JA, Morgan RO, Shaib Y, McGlynn KA, El-Serag HB. Diabetes increases the risk of hepatocellular carcinoma in the United States: a population based case control study. Gut 2005;54:533-539.

31) El-Serag HB, Hampel H, Javadi F. The association between diabetes and hepatocellular carcinoma: a systematic review of epidemiologic evidence. Clin Gastroenterol Hepatol. 2006 Mar;4(3):369-80.

32) Turati F, Talamini R, Pelucchi C, et al. Metabolic syndrome and hepatocellular carcinoma risk. Br J Cancer 2013; 108: 222-28.

33) Krawczyk M, Stokes CS, Romeo S, Lammert F. HCC and liver disease risks in homozygous PNPLA3 p.I148M carriers approach monogenic inheritance. J. Hepatol. 2015; 62:980-81

34) Reddy SK, Steel JL, Chen HW, et al. Outcomes of curative treatment for hepatocellular cancer in nonalcoholic steatohepatitis versus hepatitis C and alcoholic liver disease. Hepatology 2012; 55: 1809-19.

35) Dongiovanni P, Romeo S, Valenti L. Hepatocellular carcinoma in nonalcoholic fatty liver: role of environmental and genetic factors. World J. Gastroenterol. 2014; 20:12945-55

36) Mohamad B, Shah V, Onyshchenko M, et al. Characterization of hepatocellular carcinoma (HCC) in non-alcoholic fatty liver disease (NAFLD) patients without cirrhosis. Hepatol Int. 2016 Jul;10(4):632-9.

37) Stoot JH, Coelen RJ, De Jong MC, et al. Malignant transformation of hepatocellular adenomas into hepatocellular carcinomas: a systematic review including more than 1600 adenoma cases. HPB (Oxford) 2010; 12:509-522.

38) Agrawal S, Agarwal S, Arnason $\mathrm{T}$ et al. Management of Hepatocellular Adenoma: Recent Advances. Clin Gastroenterol Hepatol. 2015 Jul;13(7):1221-30. 
39) Dokmak S, Paradis V, Vilgrain V, et al. A single-centersurgical experience of 122 patients with single and multi-ple hepatocellular adenomas. Gastroenterology 2009; 137:1698-705.

40) Vanni E, Bugianesi E. Obesity and liver cancer. Clin. Liver. Dis. 2014.18:191-203

41) Ma C, Kesarwala AH, Eggert T, Medina-Echeverz et al. NAFLD causes selective CD4(+) T lymphocyte loss and promotes hepatocarcinogenesis. Nature. 2016 Mar 10;531(7593):253-7.

42) Ip BC, Liu C, Smith DE et al.. High-refined-carbohydrate and high-fat diets induce comparable hepatic tumorigenesis in male mice. J. Nutr. 2014; 144:647-53

43) Vos M, Lavine JE. Dietary fructose in nonalcoholic fatty liver disease. Hepatology 2013; $57: 2525-31$

44) Piscaglia F, Svegliati-Baroni G, Barchetti A, HCC-NAFLD Italian Study Group Clinical patterns of hepatocellular carcinoma in nonalcoholic fatty liver disease: A multicenter prospective study. Hepatology. 2016 Mar;63(3):827-38.

45) Mittal S, Sada Y, El-Serag HB, et al. Temporal trends of nonalcoholic fatty liver disease-related hepatocellular carcinoma in the Veteran Aff airs Population. Clin Gastroenterol Hepatol 2015; 13 : 594-60.

46) Perumpail RB, Wong RJ, Ahmed A, Harrison SA. Hepatocellular Carcinoma in the Setting of Non-cirrhotic Nonalcoholic Fatty Liver Disease and the Metabolic Syndrome: US Experience. Dig Dis Sci. 2015 Oct;60(10):3142-8.

47) Marengo A, Jouness RI, Bugianesi E Progression and Natural History of Nonalcoholic Fatty Liver Disease in Adults. Clin Liver Dis. 2016 May;20(2):313-24.

48) European Association for the Study of the Liver (EASL); European Association for the Study of Diabetes (EASD); European Association for the Study of Obesity (EASO). EASL-EASD-EASO Clinical Practice Guidelines for the management of non-alcoholic fatty liver disease. J Hepatol. 2016 Jun;64(6):1388-402 
49) Heimbach J, Kulik LM, Finn R, et al. AASLD guidelines for the treatment of hepatocellular carcinoma. Hepatology. 2017 Jan 28.

50) Omata $\mathrm{M}$, Cheng AL, Kokudo $\mathrm{N}$ et al. Asia-Pacific clinical practice guidelines on the management of hepatocellular carcinoma: a 2017 update. Hepatol Int. 2017 Jul;11(4):317-370.

51) Singal AG, Yopp AC, Gupta S, et al. Failure rates in the hepatocellular carcinoma surveillance process. Cancer Prev Res 2012; 5: 1124-30.

52) Della Corte C, Colombo M. Surveillance for hepatocellular carcinoma. Semin Oncol 2012; 39: 384-98.

53) European Association for the Study of the Liver, European Organisation for Research and Treatment of Cancer. EASL-EORTC clinical practice guidelines: management of hepatocellular carcinoma. J Hepatol 2012; 56: 908-43.

54) Salomao MS, Yu WM, Brown RS, et al. Steatohepatitic hepatocellular carcinoma (SH-HCC): a distinctive histological variant of HCC in hepatitis C virus-related cirrhosis with associated NAFLD/NASH. Am J Surg Pathol 2010; 34: 1630-36.

55) CP Wen, J Lin, CY Yang, et al. Hepatocellular carcinoma risk prediction model for the general population: the predictive power of transaminases. J Natl Cancer Inst, 104 (2012), pp. 1599-1611

56) Kurmann A, Wanner B, Martens F, et al. Hepatic steatosis is associated with surgical-site infection after hepatic and colorectal surgery. Surgery 2014; 156: 109-16.

57) Viganò L, Conci C, Cescon M, et al. Liver resection for hepatocellular carcinoma in patients with metabolic syndrome: a multicenter matched analysis with HCV-related HCC. J Hepatol 2015; 63: 93-101.

58) Wong R, Aguilar M, Cheung R, et al. Nonalcoholic steatohepatitis is the second leading etiology of liver disease among adults awaiting liver transplantation in the United States. Gastroenterology 2015; 148: 547-55. 
59) Safwan M, Collins KM, Abouljoud MS et al. Outcome of liver transplantation in patients with prior bariatric surgery. Liver Transpl. 2017 Jul 28.

60) Wang X, Li J, Riaz DR Outcomes of liver transplantation for nonalcoholic steatohepatitis: a systematic review and meta-analysis. Clin Gastroenterol Hepatol. 2014 Mar;12(3):394-402

61) Wen CP, Lin J, Yang CY, et al. Hepatocellular carcinoma risk prediction model for the general population: the predictive power of transaminases. J Natl Cancer Inst 2012; 104: 1599-611

62) Piguet AC, Saran U, Simillion C, et al. Regular exercise decreases liver tumors development in hepatocyte-specific PTEN-deficient mice independently of steatosis. J Hepatol 2015; 62: 1296-303.

63) Mousa SA, Aljada A. Metformin and neoplasia: implications and indications. Pharmacol Ther 2011.

64) Zhang ZJ, Zheng ZJ, Shi R, et al. Metformin for liver cancer prevention in patients with type 2 diabetes: a systematic review and meta-analysis. J Clin Endocrinol Metab 2012; 97: 2347-353

65) Zhang H, Gao C, Fang L, et al. 2013. Metformin and reduced risk of hepatocellular carcinoma in diabetic patients: a meta-analysis. Scand. J. Gastroenterol. 48:78-87

66) Chen TM, Lin CC, Huang PT, Wen CF. Metformin associated with lower mortality in diabetic patients with early stage hepatocellular carcinoma after radiofrequency ablation. J Gastroenterol Hepatol 2011;26:858-865.

67) Singh S, Singh PP, Singh AG, et al. Statins are associated with a reduced risk of hepatocellular cancer: a systematic review and meta-analysis. Gastroenterology 2013; 144: 323-332.

68) Degasperi E, Colombo M, Distinctive features of hepatocellular carcinoma in non-alcoholic fatty liver disease. Lancet Gastroenterol Hepatol. 2016 Oct;1(2):156-164. 
69) Bugianesi E, Leone N, Vanni E et al. Expanding the natural history of nonalcoholic steatohepatitis: from cryptogenic cirrhosis to hepatocellular carcinoma. Gastroenterology. 2002 Jul;123(1):134-40.

70) Marrero JA, Fontana RJ, Su GL, et al. NAFLD may be a common underlying liver disease in patients with hepatocellular carcinoma in the United States. 2002. Hepatology 36:1349-54

71) Tateishi R, Okanoue T, Fujiwara N, et al. Clinical characteristics, treatment, and prognosis of non-B, non-C hepatocellular carcinoma: a large retrospective multicenter cohort study. J. Gastroenterol. 2015.50:350-60

72) Archambeaud I, Auble H, Nahon P et al Risk factors for hepatocellular carcinoma in Caucasian patients with non-viral cirrhosis: the importance of prior obesity. Liver Int. 2015 Jul;35(7):1872-6.

73) Kasmari AJ, Welch A, Liu G et al. Independent of Cirrhosis, Hepatocellular Carcinoma Risk Is Increased with Diabetes and Metabolic Syndrome. Am J Med. 2017 Jun;130(6):746.e1-746.e7.

74) Koh WP, Wang R, Jin A et al. Diabetes mellitus and risk of hepatocellular carcinoma: findings from the Singapore Chinese Health Study. Br J Cancer. 2013 Mar 19;108(5):1182-8. 